\title{
Estratégias sintáticas no português falado: construções adverbiais na conversação
}

Syntactic strategies in spoken Portuguese: adverbial constructions in conversation

\author{
Ana Lima*
}

\begin{abstract}
RESUMO: Um rápido levantamento bibliográfico sobre questões sintáticas evidencia que a grande maioria dos trabalhos publicados toma como objeto de análise a língua escrita, sendo menos numerosos os estudos que põem em exame fenômenos sintáticos tendo como base um corpus de língua falada, e menos ainda do português falado. Visando contribuir para a diminuição dessa lacuna, este trabalho pretende apresentar uma síntese dos resultados de pesquisa sobre o funcionamento textual e discursivo das construções adverbiais no português brasileiro falado, mais especificamente na conversação face a face. A fim de atingir os objetivos a que se propõe, este estudo fundamenta-se em alguns pressupostos funcionalistas, tomando como princípio geral o de que a gramática é "sensível às pressões do uso" (NEVES, 1997), o que significa dizer que o falante organiza gramaticalmente suas expressões linguísticas com base não apenas no conhecimento que tem acerca do sistema de sua língua, mas, principalmente, nos propósitos comunicativos que almeja alcançar na interação verbal. A análise aqui empreendida corrobora a hipótese de que a opção pelo emprego de uma construção adverbial, pelo falante, visa atender a seus propósitos comunicativos,

ABSTRACT: A quick survey of the literature on syntactic issues shows that the vast majority of published works takes as their object of analysis written language, with relatively few studies that examine syntactic phenomena based on a corpus of spoken language, and even fewer of the spoken Portuguese language. Aiming to address this deficiency, this paper intends to provide a summary of the results of research on the textual and discursive functioning of adverbial constructions in spoken Brazilian Portuguese, more specifically in face-to-face conversation. In order to achieve this goal, this study is based on certain functionalist assumptions, taking as a general principle that the grammar is "sensitive to the pressures of use" (NEVES, 1997). This means that speakers organize grammatically their linguistic expressions based not only on their knowledge about the system of the language, but mainly on the communicative purposes that they aim to achieve in verbal interaction. The analysis undertaken here supports the hypothesis that the choice of employing an adverbial construction serves the speaker's communicative purposes, and that these purposes only emerge in the course of conversation.
\end{abstract} propósitos esses que só emergem no curso da conversação.

PALAVRAS-CHAVE: Língua portuguesa; sintaxe; conversação; construções adverbiais.

KEYWORDS: Portuguese language; syntax; conversation; adverbial constructions.

\section{Introdução}

Em uma visão tradicional, é consensual a ideia de que as orações podem estar relacionadas por meio de dois mecanismos gerais, referidos como 'coordenação' e

\footnotetext{
* Doutora em Linguística e Língua Portuguesa; vinculada ao Depto. de Letras da Universidade Federal de Pernambuco (UFPE).
} 
‘subordinação'. A ‘subordinação’ é, geralmente, estudada de forma tripartida, subdividindo-se em subordinação substantiva, adjetiva e adverbial.

Este trabalho pretende apresentar os resultados de pesquisa que se deteve na investigação das construções de natureza adverbial. Neste estudo, a expressão 'construções adverbiais' é utilizada, em preferência àquilo que a tradição tem chamado de 'orações subordinadas adverbiais', para fazer referência a segmentos nos quais se evidenciam relações de natureza adverbial, a despeito da ausência de qualquer elemento conectivo formal. Isso acontece, por exemplo, nas ocorrências (1) e (2), apresentadas abaixo, nas quais podem ser inferidas relações de causa e de condição, respectivamente:

(1)

Loc - aqui por exemplo... a gente come banana a gente acha banana aqui mais comum laranja né?... lá é fruta-de-conde que aqui agora está bem cara $\downarrow$... outro dia eu estive tentando comprar uma eram quinze cruzeiros uma fruta-de-conde eu até desisti $\downarrow$... (DID 328/RJ)

(2)

L1 - conseguiram... com o SOro recolhido de uma das pessoas que contraíra a febre e: que ficara boa... debelar... até... certo ponto $\downarrow$... e isola:ram... o danado do vírus da Febre de Lassa que é um um: um:... um micro-organismo éh:: parecido com a bola de boli/ de: bilhar $\downarrow$...

L2 - não FO:ra... a rapidez dos transportes...

L1- o que é que tá aconte cendo?...

L2 -

esse vírus jamais teria sido isolado $\downarrow . .$. (D2 005/RE)

Um rápido levantamento bibliográfico sobre as construções adverbiais mostra que a grande maioria dos trabalhos publicados, de correntes teóricas diversas, toma como objeto de análise a língua escrita, sendo menos numerosos os estudos que põem em exame essas construções com base em um corpus de língua falada, e menos ainda do português falado.

Com vistas a um estudo integrado, ou seja, um estudo que levasse em conta critérios sintáticos, semânticos e pragmáticos, e visando a contribuir para a descrição e compreensão dos fenômenos da modalidade falada do português brasileiro, a pesquisa aqui empreendida centrouse, especificamente, no funcionamento das construções adverbiais na conversação face a face, e fundamentou-se em alguns pontos da Teoria Funcionalista, tendo como principal pressuposto teórico o de que a gramática é "sensível às pressões do uso" (NEVES, 1997), o que significa dizer que o falante organiza gramaticalmente suas expressões linguísticas com base não apenas no conhecimento que tem acerca do sistema de sua língua, mas principalmente nos propósitos 
comunicativos que almeja alcançar na interação. Desse pressuposto decorre que: (1) a reflexão gramatical não pode deixar de considerar o papel primordial das condições de produção do texto na organização dos enunciados, aí incluídos os papéis do falante e do(s) seu(s) interlocutor(es); (2) na interação verbal, a expressão linguística tem o papel de mediadora entre a intenção do falante e a interpretação do(s) ouvinte(s). Disso decorre que as escolhas que faz o falante podem ser analisadas como reveladoras de uma intenção, que, por sua vez, reflete as relações sociais estabelecidas.

Como o objetivo da pesquisa foi o de investigar as construções adverbiais na interação verbal, mais especificamente na conversação face a face, optamos por selecionar como material empírico alguns inquéritos do arquivo sonoro do Projeto da Norma Linguística Urbana Culta NURC. Como se sabe, o acervo do Projeto NURC (nas cinco capitais brasileiras em que o Projeto foi instituído: Porto Alegre, São Paulo, Rio de Janeiro, Salvador e Recife), é constituído de três tipos de inquéritos:

- diálogo entre informante e documentador (DID), que corresponde a uma espécie de entrevista, em que o informante deve falar sobre um determinado tema proposto pelo documentador;

- diálogo entre dois informantes (D2), em que duas pessoas conversam livremente sobre um tema apresentado pelo documentador;

- elocução formal (EF), que consiste em gravação de aulas, conferências, palestras etc.

Para compor o corpus da presente pesquisa, foi selecionado 01 (um) inquérito dos tipos DID e D2 de cada uma das cinco cidades brasileiras abrangidas no Projeto NURC, o que perfez um total de dez inquéritos, sendo assim especificados: de Porto Alegre (POA) - 121/DID e 291/D2; de São Paulo (SP) - 234/DID e 360/D2; do Rio de Janeiro (RJ) - 328/DID e 355/D2; de Salvador (SSA) - 231/DID e 98/D2; e de Recife (RE) - 216/DID e 005/D2.

As elocuções formais (EFs) não foram selecionadas para integrar o corpus porque, apresentando um grau mínimo de envolvimento entre os interlocutores, bem como alto grau de assimetria e de planejamento prévio, foram consideradas pouco representativas do gênero "conversação face a face".

Apesar de o material selecionado estar inteiramente transcrito (e alguns inquéritos terem sido já publicados), algumas transcrições exigiram uma acurada revisão. Por isso, a fim de assegurar a fidelidade das transcrições em relação ao material sonoro, a primeira fase da análise consistiu na audição de todo o material selecionado, o que representou um total de nove horas 
e cinquenta e dois minutos de escuta. Em seguida, foram selecionados segmentos nos quais construções adverbiais podiam ser evidenciadas, o que totalizou 1.275 ocorrências.

Uma vez selecionados, os dados foram submetidos a uma análise qualitativa, buscandose averiguar, principalmente, o funcionamento das construções adverbiais na interação face a face. Dessa maneira, o que se pôs em análise foi a dinâmica da conversação, da qual as construções adverbiais participam, sendo uma das estratégias empregadas para a obtenção dos resultados de sentido pretendidos pelos interlocutores. Análises quantitativas foram realizadas para subsidiar a análise qualitativa, tendo sido os resultados numéricos (percentuais) de grande relevância, por corroborar as conclusões deste estudo.

Quanto à maneira de apresentarem-se as ocorrências, optamos por seguir, neste trabalho, as normas gerais de transcrição adotadas pelo Projeto NURC no Brasil ${ }^{1}$, mantendo-se os mesmos sinais. No entanto, não havendo nas normas do Projeto NURC sinal indicativo da "pausa de final de frase", que marca a completude de um enunciado (ainda quando não há troca de turnos entre os interlocutores), e sendo esse um dado relevante para a presente análise, um sinal representativo desse tipo de pausa foi criado, e aparece nos exemplos como uma seta apontando para baixo $(\downarrow)$.

\section{A língua falada: considerações gerais}

Não resta dúvida de que a tradição escolar tem prestigiado a língua escrita em relação à falada. Isso foi comprovado por Marcuschi (1997), que, após investigar mais de 12.000 páginas de 58 manuais didáticos do português, chegou à conclusão de que à língua falada esses manuais dedicam, em linhas gerais, a insignificante marca de $2 \%$, no cômputo total de páginas.

A situação seria menos preocupante se esse parco índice se devesse a uma simples indiferença da sociedade brasileira pela modalidade falada da língua. No entanto, o que se observa é que ele é resultado de uma atitude extremamente negativa em relação à fala, que, a despeito da posição central que ocupa no dia a dia das pessoas, ainda é considerada "o lugar do erro" (MARCUSCHI, 1995, p.1195) ou um “antimodelo” (MARCUSCHI, 1997, p.40).

Parte da responsabilidade por essa visão deturpada da modalidade falada deve-se à própria tradição dos estudos linguísticos, uma vez que até há pouco tempo a Linguística tomava como objeto de análise ou a escrita ou um modelo de fala idealizada, artificial, e não a fala

\footnotetext{
${ }^{1}$ Em Salvador, o Projeto NURC adotou regras de transcrição que divergem daquelas adotadas nas outras capitais.
} 
autêntica. Podemos afirmar que, hoje, o posicionamento teórico dos estudos linguísticos encontrou um ponto de equilíbrio, no sentido de dar à fala a relevância que ela merece nos estudos da linguagem humana, sem incorrer no erro de, por causa disso, detrair a escrita.

O nível de conhecimento que se tem hoje sobre língua e linguagem atesta que já não é cabível observar a fala pela perspectiva da escrita, ou vice-versa. Defender, hoje, que língua falada e língua escrita se opõem de forma dicotômica, sendo produzidas em situações polares (MARCUSCHI, 1999a), é, no mínimo, um anacronismo.

Não têm mais sentido os exercícios de "tradução", que tinham por base a concepção equivocada de que a diferença entre a fala e a escrita era apenas uma questão de mídia diferente (BLANCHE-BENVENISTE, 1995). Considera-se, atualmente, que fala e escrita são atividades altamente relevantes, cada uma com características e finalidades próprias, sendo, ambas, modalidades diversas de um mesmo sistema linguístico. Nem a escrita é a representação gráfica da fala, nem a fala é a escrita em sua representação sonora.

A esse respeito, são concludentes as seguintes observações de Marcuschi:

Oralidade e escrita são práticas e usos da língua com características próprias, mas não suficientemente opostas para caracterizar dois sistemas linguísticos nem uma dicotomia. Ambas permitem a construção de textos coesos e coerentes; ambas permitem a elaboração de raciocínios abstratos e exposições formais e informais, variações estilísticas, sociais, dialetais e assim por diante. As limitações e os alcances de cada uma estão dados pelo potencial do meio básico de sua realização: som de um lado e grafia de outro, embora elas não se limitem a som e grafia. (MARCUSCHI, 2001, p.17)

Assim, o quadro a que assistimos atualmente, no Brasil, é o dos estudiosos da fala envidando esforços para fazer constar as reflexões sobre a língua falada nos estudos de língua portuguesa em todos os níveis escolares. O que se deseja, na fase atual das reflexões sobre a língua, é que a fala seja percebida como aquilo que realmente é, livre do peso prescritivonormativo que tem a escrita padrão ensinada pela escola.

Porém, apesar dos inquestionáveis avanços no sentido de valorizar-se a língua falada, permanecem resquícios de uma tradição que nos habituou a perceber as relações entre fala e escrita de maneira dicotômica. Assim, além daqueles que insistem em relacionar a fala com o uso de uma variedade não padrão, há ainda os que resistem à ideia de considerar a fala como uma modalidade sistematizada e, do mesmo modo que a escrita, regida por uma série de normas. Essa resistência deve-se, principalmente, à equivocada interpretação do termo "norma". Ao 
afirmar-se que a fala é regida por normas, esse último termo não deve ser entendido de maneira restrita, ou seja, como referência às prescrições apontadas nos manuais, mas deve ser interpretado como um termo que faz referência tanto às restrições do sistema como às regras atreladas às relações sociais que subjazem a todas as situações de interação.

Desse modo, as características próprias da fala, como repetições, hesitações, correções e truncamentos na estrutura não podem servir de base para a afirmação de que ela não possui normas. Nem mesmo a chamada "fala padrão" está isenta de apresentar as características típicas da oralidade, como afirma Marcuschi (1995). Mais de acordo com os estudos linguísticos atuais, portanto, é defender que, ao se aludir às normas da fala e/ou da escrita, deixe-se bem claro a que normas se está referindo. Isso porque, do ponto de vista descritivo, cada variedade tem suas próprias normas. Do ponto de vista da norma prescritiva, entretanto, as afirmações sobre a fala precisam necessariamente refletir uma cuidadosa investigação, que leve em conta aspectos sociais e interacionais diversos. Sob esse ponto de vista, tanto a fala quanto a escrita apresentam variações que percorrem um contínuo que vai do padrão ao não padrão (RODRIGUES, 1995).

Outra preocupação que norteou as pesquisas sobre a língua falada, inicialmente analisada segundo os parâmetros da escrita, foi a tentativa de descobrir qual dessas modalidades apresentaria maior grau de complexidade. Em geral, as primeiras conclusões tendiam a defender que a escrita é mais complexa. Logo em seguida, novos estudos revelavam que a fala, se não é mais complexa do que a escrita, é pelo menos tão complexa quanto ela. Sobre essa questão, ainda hoje não se pode dizer com toda a certeza que os estudiosos chegaram a um consenso.

Permanece, subjacente aos manuais e gramáticas de língua portuguesa, a crença de que a escrita é estruturalmente elaborada e complexa, enquanto a fala é estruturalmente simples. Dentre os linguistas, porém, há os que julgam que a fala é mais complexa do que a escrita. Nesse aparente impasse, cabe a pergunta: Que noção de complexidade está sendo discutida?

Beaman (1982), por exemplo, discute complexidade no nível sintático apenas, e parte da ideia, geralmente aceita, de que complexidade sintática é função do número e do tipo de encaixamentos presentes em um texto. Procede, então, a um levantamento da quantidade de estruturas coordenadas e de subordinadas em narrativas faladas do inglês, chegando à conclusão de que, contrariamente ao que se imagina, a fala, como um todo, é tão complexa quanto a escrita, se não mais do que esta. 
Para Halliday (1985; 1989), é um erro pensar na língua escrita como altamente organizada, estruturada e complexa, e na língua falada como desorganizada, fragmentada e simples. De acordo com seu ponto de vista, a língua falada é tão altamente organizada quanto a língua escrita, e é capaz de alcançar o mesmo grau de complexidade. Apenas - segue o autor - ela é complexa de um modo diferente: enquanto a complexidade da escrita reside em sua “densidade lexical”, a da fala está em seu "emaranhado (enredamento) gramatical”. Em outras palavras, Halliday (1989) postula que, pelo fato de na língua falada grande parte do sentido ser expresso pela gramática, e não pelo vocabulário, a estrutura da frase (sentence) alcança nessa modalidade uma complexidade raramente alcançada pela escrita. Defende, então, que, ao investigar-se complexidade, a conclusão deverá apontar para o fato de que cada modalidade é complexa de sua própria maneira.

\section{A sintaxe da língua falada}

A tradição gramatical, cuja ênfase é o estudo da língua escrita, atribui a essa modalidade a característica de possuir uma organização sintática. Os estudos sobre a fala revelam que essa não é uma característica exclusiva da escrita, mas também se encontra no texto falado.

A impressão de caos que se tem ao analisar a fala pela primeira vez não decorre, certamente, da ausência de organização sintática dessa modalidade. O "falso caos" da fala é consequência, sim, das suas condições de produção, que, afetando inevitavelmente a sua estrutura gramatical, são responsáveis pelas características específicas do texto falado. Hesitações, correções, repetições, truncamentos etc., típicos da fala, não devem ser vistos como marcas de "ausência de sintaxe" ou de "agramaticalidade". Pelo contrário, devem ser percebidos como componentes do texto falado, que desempenham nele importantes papéis, tanto formais quanto cognitivos e interacionais (FÁVERO et al., 1999b; MARCUSCHI, 1999b).

Há autores (BROWN \& YULE, 1983; KOCH, 1998) que, embora percebam que ambas as modalidades apresentam uma "sintaxe", tratam de maneira diversa a sintaxe da fala e a sintaxe da escrita. Para Castilho (1993; s/d; 1998), as características da língua falada, em especial da conversação, são decorrentes, em primeiro lugar, do fato de ela resultar de um "diálogo em presença", do qual decorre que o discurso vai sendo construído em concomitância com o processo dinâmico da interação, ressentindo-se fortemente desse processo, no sentido de os enunciados refletirem pressões de natureza sociointeracional. Em segundo lugar, do fato de 
a fala "documentar os dois momentos fundamentais da linguagem: planejamento e execução". Dessa característica, afirma Castilho (1993), resulta a impressão geral de que a fala não apresenta estruturas sintaticamente organizadas.

Uma questão frequentemente aludida quando se deseja explicar as descontinuidades da língua falada é a que diz respeito ao "planejamento" ou "não planejamento" da fala. Acreditavase, no início dos estudos sobre essa modalidade, que a grande quantidade de segmentos truncados nela presentes seria resultado da falta de planejamento dessa atividade linguística. Estudos como o de Ochs (1979), no entanto, mostram que, na atividade discursiva, planejamento não é uma questão de tudo ou nada, e sim uma questão de graus. É então consensual, atualmente, a compreensão de que há vários graus de planejamento do discurso, numa escala que vai do muito planejado ao pouco planejado, quer na escrita quer na fala.

Assim, o máximo que se pode afirmar sobre a relação entre planejamento e modalidades da língua é que, enquanto a escrita tem uma tendência para o mais planejado e para um planejamento anterior à execução, a fala tende para o menos planejado e para o planejamento local, concomitante à execução, isso devido a características de uma e de outra modalidade.

Além disso, alguns linguistas (HALLIDAY, 1985; MARCUSCHI, 1995) fazem uma distinção fundamental entre produto e processo. A relevância dessa distinção para o presente estudo reside no fato de que ela corresponde à visão fortemente arraigada de que o texto escrito é um produto, e o texto falado, um processo. Como a tradição relaciona gramática com a modalidade escrita da língua, a concepção geral de gramática tem sido sempre a de uma "gramática do produto". Dessa maneira, tende-se a pensar que a fala, sendo um processo, prescinde de gramática, e a considerar que daí procede a aparente desordem do texto falado.

Esquece-se, no entanto, de que a aparente desordem da fala nada mais é do que a evidência de que não se apagam, nessa modalidade, as marcas do processo. $\mathrm{Na}$ escrita, ao contrário, essas marcas raramente estão presentes no produto final, o que não significa que o texto escrito prescinde de uma fase de elaboração, na qual, assim como no texto falado, são comuns as correções, os truncamentos, as hesitações, etc.

Segundo Castilho (1997), há, entre os linguistas brasileiros que se dedicam ao estudo da língua falada, um consenso de que "a melhor abordagem dessa modalidade é considerar os processos de criação linguística que ela documenta, antes que descrever seus produtos”. Todos os estudiosos da modalidade oral são unânimes em reconhecer a língua falada como "um 
conjunto de processos". Desvendar esses processos é que tem sido, para os estudiosos da fala, o grande desafio.

\section{A conversação: considerações gerais}

Devido à sua alta frequência no cotidiano das pessoas, a conversação tem o estatuto de "atividade linguística básica". Além de ser a atividade linguística mais frequente na vida diária das pessoas, ela tem um papel fundamental no processo de aquisição de uma língua, fato que é ressaltado por Levinson (1983), que a ela se refere como "a matriz para a aquisição da língua", já que é a atividade à qual o ser humano se expõe em primeiro lugar.

Preti (2002) concebe a conversação como uma atividade que se insere em outra atividade mais abrangente, a interação, a qual, para ele, corresponde à "reciprocidade do comportamento das pessoas, quando em presença umas das outras, numa escala que vai da cooperação ao conflito" (PRETI, 2002, p.45). Para ele, conversação é um rótulo sob o qual podem abrigar-se diversas atividades de comunicação verbal, desde as conversas informais, distensas e descompromissadas do dia a dia até os diálogos mais formais, com temas predeterminados.

Quer seja entre dois interlocutores apenas, quer seja com a participação de um grupo maior de pessoas, a conversação é uma "via de mão dupla", na qual locutor e interlocutor vão criando, simultaneamente, um texto. Assim, se fosse possível "congelar" (como um instantâneo) o produto final da interação conversacional, de tal modo que ele não perdesse nenhuma de suas características, o que se exibiria seria um texto cuja autoria teria que ser compartilhada por tantos quantos fossem os participantes daquele evento.

A ideia de que a conversação é uma atividade colaborativa, em todos os aspectos, está presente em diversos trabalhos publicados (VANDERVEKEN, 2000; LAKOFF, 1984). Segundo Castilho (1993), a atividade conversacional obriga o interlocutor a "preencher vazios" a todo momento. É evidente que esse preenchimento de vazios por parte do interlocutor não implica que ele vai dando ao texto que recebe uma feição canônica, fazendo-o caber dentro das regras gramaticais que são habitualmente aplicadas à escrita, mas, sim, que vai aplicando automaticamente ao texto que recebe seus conhecimentos sobre a língua (linguísticos e sociopragmáticos), de modo a poder compreendê-lo e interpretá-lo. Do lado do ouvinte, então, a apreensão dos vários sentidos pretendidos pelo locutor depende tanto (se não mais) da dinâmica da interação quanto das formas escolhidas pelo falante para veicular as ideias. 
Outra observação importante sobre a conversação é que ela tende a maximizar o uso de informações compartilhadas e a ancorar-se fortemente na situação em que ocorre. Dessa maneira, o dinâmico processo de trocas que constitui a interação conversacional é o principal responsável pela construção dos sentidos durante a conversação. Por causa dessa relevância da interação na construção dos sentidos, pode-se dizer que o fato de amputar-se a conversação de seu contexto real, com a finalidade de analisá-la, representa uma perda parcial de muitos de seus elementos significativos.

Outra característica relevante da conversação, apontada por Marcuschi (1995), é o seu complexo sistema de troca de turnos. Hilgert (2001) observa que os turnos "não são pequenos monólogos dirigidos a um interlocutor e dele independentemente produzidos". Ao contrário, durante a conversação, a produção de um novo turno, pelos interlocutores, é motivada por alguma intenção comunicativa, pela qual se tenciona influenciar, ou modificar, de alguma forma, o(s) seu(s) parceiro(s).

É importante salientar que essa troca não corresponde ao intercâmbio de material verbal apenas, mas de uma enorme quantidade de material não verbal, como gestos, olhares e movimentos corporais diversos, o que faz da conversação um evento extremamente complexo, no qual os sentidos são construídos a partir da combinação de elementos linguísticos, cognitivos, psicossociais e culturais.

Há que se ressaltar, ainda, o contínuo trabalho de monitoramento que se realiza no decorrer da conversação, por todos os participantes. O falante monitora as expressões linguísticas já produzidas, as que estão sendo produzidas no momento da fala, o efeito dessas expressões para o ouvinte, as reações do ouvinte em relação a fatores contextuais, que fogem do controle do falante, ao mesmo tempo em que planeja o próximo enunciado. Do lado do ouvinte, a conversação o obriga a monitorar as expressões linguísticas que recebe, para planejar possíveis intervenções, as “intenções" do falante, os dados contextuais, o melhor momento para assumir o papel de falante, etc.

Dessa maneira, a conversação se configura como uma atividade cuja execução aciona uma multiplicidade de processos e estratégias, que agem simultaneamente. Entendendo, então, a organização gramatical como uma das características da conversação, cabe averiguar que gramática é essa. Analisemos, como parte do estudo dessa gramática, as construções adverbiais. 


\section{As construções adverbiais na conversação: análise de dados}

A pesquisa que serviu de base para este estudo buscou averiguar, principalmente, a contribuição das construções adverbiais para administrar e manter a conversação e os papéis sociais dos participantes nela envolvidos. Assim, a análise procurou ser eminentemente qualitativa. No entanto, à medida que procedemos a um levantamento quantitativo dos dados, para subsidiar a análise pretendida, ficou evidente que alguns deles mereciam um tratamento diferenciado, devido à relevância que demonstravam para a compreensão do fenômeno em estudo.

Decidimos, então, como opção metodológica, subdividir esta seção em duas grandes partes: na primeira, apresentam-se conclusões e comentários emanados a partir dos resultados quantitativos (numéricos) das ocorrências; na segunda, serão expostos os resultados da análise qualitativa das ocorrências, que corresponde à investigação do papel das construções adverbiais na dinâmica da conversação.

\subsection{Análise quantitativa dos dados}

Analisando a frequência das construções adverbiais nos dados do corpus, a primeira observação que se pode fazer é que esse é um tipo de construção abundante na conversação, tendo sido registradas 1.275 ocorrências em 523 porções de texto conversacional selecionadas dos 10 (dez) inquéritos analisados.

Essa frequência alta encontrada nos dados contradiz a ideia de que, devido à sua complexidade, "a subordinação é um processo que tende a ser evitado na fala" (FERNANDES \& PETIOT, 1994). Por outro lado, está em consonância com os resultados encontrados por Ford (1993), que, analisando as "orações adverbiais" na interação em inglês, concluiu que, nessa língua, elas são "a estratégia mais usada para operar conjunção na conversação".

No que se refere ao português brasileiro, a análise a que procedemos neste estudo indica que relações adverbiais emergem por todo o texto conversacional, codificadas por diversos meios, e cumprem várias funções, às quais nos reportaremos adiante. As construções adverbiais selecionadas no corpus codificam um conjunto não muito numeroso de relações semânticas, as quais podem ser agrupadas em apenas 06 (seis) classes. A Tabela 1, a seguir, mostra as classes identificadas no corpus em análise, por ordem decrescente de frequência. 
Tabela 1 - relações semânticas identificadas no corpus.

\begin{tabular}{|c|c|c|}
\hline RELAÇÃO SEMÂNTICA & \multicolumn{2}{|c|}{ FREQUÊNCIA } \\
\hline causalidade (causa lato sensu) & 586 & $(46,0 \%)$ \\
\hline tempo & 225 & $(17,7 \%)$ \\
\hline finalidade (ou propósito) & 212 & $(16,6 \%)$ \\
\hline condição & 143 & $(11,2 \%)$ \\
\hline concessão & 64 & $(5,0 \%)$ \\
\hline comparação & 45 & $(3,5 \%)$ \\
\hline TOTAL & & 1275 \\
\hline
\end{tabular}

\section{A) Relações de causalidade}

Como se pode observar pela Tabela 1, essa é a classe que abrange o maior número de ocorrências, correspondendo quase à metade das relações selecionadas. "Causalidade" designa um tipo de relação em que duas partes se inter-relacionam de maneira que uma delas é dada como a causa, e a outra como a consequência. O falante dispõe, na língua, de uma grande variedade de recursos para o estabelecimento da causalidade. Os resultados aqui encontrados mostram que a indicação de causalidade por meio de construções adverbiais é um recurso bastante utilizado na conversação face a face.

Se o falante optar por expressar causalidade por meio de uma construção adverbial, ela pode ser configurada de diversas maneiras, conforme mostra a Tabela 2, apresentada abaixo.

Tabela 2 - expressão da causalidade.

\begin{tabular}{|c|c|}
\hline CONECTIVO & FREQUÊNCIA \\
\hline porque & $493(84,1 \%)$ \\
\hline que & $35(6,0 \%)$ \\
\hline como & $29(5,0 \%)$ \\
\hline já que & $09(1,5 \%)$ \\
\hline pois & $02(0,3 \%)$ \\
\hline por [+ infinitivo] & $02(0,3 \%)$ \\
\hline devido a [+ infinitivo] & $01(0,2 \%)$ \\
\hline sem conectivo (causa implícita) & $07(1,2 \%)$ \\
\hline gerúndio & $06(1,0 \%)$ \\
\hline casos marginais & $02(0,3 \%)$ \\
\hline TOTAL & \\
\hline
\end{tabular}

A Tabela 2 revela que porque é o conectivo mais empregado para expressar relações de causalidade, sendo o elemento prototípico para essa relação. Sobre esse conectivo, no entanto, há ainda muito a ser investigado, a fim de se conseguir explicar os seus variados empregos. Em geral, descrevem-se duas funções para o porque: 
1. a de conectivo causal, quando introduz uma relação tal que uma oração é posta como sendo a "causa real" de outra, formando um enunciado complexo, como em (3):

(3)

Loc - [...] animais curiosos... curioSÍssimos há por exemplo na Austrália $\downarrow$... a fauna australiana... é chamada uma fauna de fósseis vivos... animais fósseis vivos $\downarrow$... o Ornithorhyncus paradoxius $\downarrow$... você já ouviu falar $\downarrow$... é aquele animal da Austrália... que tem sessenta setenta centímetros de comprimento $\downarrow$... ornithor... ave $\downarrow$... rhynco rinu nariz $\downarrow$... nariz de ave é bico $\downarrow$... paradoxius porque ele é paradoxal $\downarrow$... ele parece uma ave porque tem bico de pato... pés de pato... põe ovos... como as aves e como os répteis... mas não é ave $\downarrow$... paradoxalmente ele é um mamífero $\downarrow$... porque tem pelos $\downarrow$... o pelo é importante $\downarrow$... TODO mamífero tem que ter pelo $\downarrow$... (DID 216/RE)

Nessa ocorrência, o estado de coisas expresso em porque tem pelos é dado como causa real para o estado de coisas expresso em ele é um mamífero. Essa "causa real" é ratificada no enunciado posterior TODO mamífero tem que ter pelo. Do ponto de vista lógico, a sequência de orações expressas em (3) formam um silogismo perfeito, em ordem inversa.

PREMISSA $1 \Rightarrow$ Todo mamífero tem que ter pelo.

PREMISSA 2 =>

Ele tem pelos.

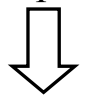

DEDUÇÃO $\Rightarrow$ Ele é um mamífero.

2. A de operador argumentativo, quando porque encadeia dois atos de fala, como em (4), abaixo.

(4)

L1 - [...] agora a Estela vive dançando... e ela quer ser bailarina $\downarrow$... agora não há que não é que haja aquele::... aquela:: aversão à vida artística... sabe? eu s/ é que a gente lê:: e::: sabe das dificuldades que o artista encontra $\downarrow$

L2 -

L1 - então eu estou procurando eh... encaminhá-la pra outra coisa não sei mas... éh ginástica rítmica por exemplo... ela:.... faz ginástica rítmica $\downarrow$... então ainda:.... eu hesito em pôr no balé mas eu vou ter que pôr sabe?... éh não quis pô-la até agora mas ela é MUIto:.... quebradi::nha ela:: faz os tre jeitos e::

L2 -

L1 - vira pirueta e faz... parece de borracha $\downarrow$...

ahn ahn

L2 - mas você sabe que é interessante pôr? porque na maiori/ na grande maioria das vezes... aquilo se torna tão chato que a criança desiste $\downarrow$... (D2 360/SP) 
Nessa ocorrência, o segmento introduzido pelo porque não é a causa de um estado de coisas, mas justifica o ato de fala você sabe que é interessante pôr? - uma pergunta. Sweetser (1990) já tinha chamado a atenção para a possibilidade de o porque atuar em vários domínios. Entretanto, segundo Paiva (1995), mesmo uma análise como essa, em diferentes domínios, não é suficientemente abrangente para dar conta da diversidade de ocorrências do porque na fala.

Quanto à posição, a ordem preferencial das construções causais introduzidas por porque, que e pois é após a oração nuclear. Nos estudos de base funcionalista em que se relaciona a ordem dos satélites com a distribuição da informação nos enunciados, postula-se que a posição posposta tende a veicular a informação nova. É o que se verifica nos dados aqui analisados. Em (5), por exemplo, o locutor responde negativamente a uma pergunta direta do documentador, e acrescenta, como informação nova, a justificativa para sua resposta, na forma de uma construção causal.

(5)

Doc. - e tu acha que o rádio a pilha tem alguma desvantagem em relação ao outro? Loc. - não eu acho que não inclusive eu acho que tem mais vantagem porque a gente pode levar em qualquer lugar $\downarrow$... se a gente é muito fanática leva em qualquer lugar ((ri)) (DID 121/POA)

Mas nem todas as construções causais têm a posposição como ordem preferencial. Nos dados analisados, $100 \%$ das ocorrências causais com como foram antepostas. Além desses dados, em 07 (sete) ocorrências, devido à ausência de elemento conectivo introdutório, a relação causal está implícita, ou seja, é apenas inferida. É o que se observa em dois trechos da ocorrência (6), apresentada a seguir.

(6)

Loc. - agora eu tenho $\mathrm{u} / \mathrm{a}$ as minhas amigas vão vão sempre a teatro $\downarrow$ quase... quase sempre elas vão quase todo domingo $\downarrow$ eu:: sou um pouco preguiçosa não vou $\downarrow$ prefiro ficar assi/ a a aqui assistindo televisão ou dormindo ou lendo o jornal $\downarrow$... mas elas::/ e comentam comigo $\downarrow$ a I. diz que tem assistido várias peças mas eu não tenho eu PArei um pouco de ir agora $\downarrow$... sei lá ando muito cansada não tenho ido mais a teatro $\downarrow$ (DID 234/SP)

É importante observar que as construções causais introduzidas pelo conectivo que são consideradas, pelas gramáticas tradicionais, como "coordenadas explicativas". Não se evidenciou, entretanto, para essas construções, um funcionamento que justificasse a sua exclusão da análise, já que operam, tanto quanto o porque, no estabelecimento de uma relação 
causal no domínio dos atos de fala. Observe-se, por exemplo, a possibilidade de substituição do conectivo que pelo conectivo porque na ocorrência (7), abaixo, em que se relacionam dois atos de fala.

\section{(7)}

L1 - mas vamos começar pelas pelas viagens... que de bote a remo não precisa né? já vamos começar por bote por b/ por b/ por barco a vela $\downarrow$... (D2 005/RE)

\section{B) Relações de tempo}

As construções de valor temporal ocorrem, nos dados analisados, em segundo lugar no que se refere à frequência. Na verdade, a análise revela que em qualquer ponto do texto conversacional é possível reconhecerem-se indicações temporais, as quais podem ser inseridas na conversação por variados meios, dentre os quais encontramos a construção adverbial.

A função básica das construções temporais é alocar um estado de coisas em algum ponto na linha do tempo. Se o falante opta, pois, por fazer uma circunstanciação de tempo empregando uma construção adverbial, os dados mostram que ela é, na grande maioria das ocorrências, introduzida pelo conectivo quando, sendo esse, então, o elemento prototípico para esse tipo de construção.

Estudos nos quais o quando foi posto sob análise mais acurada (Neves et al., 1993) revelam que esse elemento pode variar, formal e semanticamente, a depender dos contextos em que se encontram. Pode funcionar como conjunção temporal mesmo, operando circunstanciação, ou pode apresentar-se expandindo e reelaborando o conteúdo expresso por uma predicação. Nesses casos, sua função é apositiva, e sua feição sintática é a de uma "oração adjetiva não restritiva". De maneira geral, o nexo temporal que se estabelece entre dois estados de coisas pode expressar dois tipos de relações de tempo: simultaneidade ou não simultaneidade (Neyes, 2000). Essas relações estão exemplificadas, respectivamente, nas ocorrências (8) e (9), abaixo.

(8)

L1 - [...] agora:: o Luís... o de seis anos

L2 - ahn ahn

L1 - ele::... desde pequenino ele é ((vozes ininteligíveis)) desde pequeno o Luís gosta... da história do homem $\downarrow$... então... quando ele não sabia ler ele lia mui/ ele via as figuras da pré-história e gostava muito $\downarrow$... então ele fazia com que nós lêssemos... os livros éh:: coleções:: uma e outra que a gente tem... éh:: sobre a 
formação do mundo... sobre a a:: a fo/ a a evolução do homem e tudo mais $\downarrow[\ldots]$ (D2 360/SP)

(9)

Loc. - quando chegou o balê russo aqui em São Paulo eles pediram que as alunas do do do da Prefeitura que éramos nós... aquele grupo TOdo fosse fazer cena num num num dos números que eles apresentavam $\downarrow$ (DID 234/SP)

Construções temporais são as que mais favorecem associações de outras relações semânticas. Podem ocorrer, por exemplo, com valor condicional, como em (10), dentre outras.

(10)

Doc. - vamos falar um pouco sobre cinema você gosta de cinema?

Loc. - olha cinema eu:: gosto quando é filme:.... leve filme romântico $\downarrow$ não gosto de ver... bangue-bangue... ah:: também vejo de ye/ conforme o filme esses de:: espionagem e de poli/ policial também $\downarrow \ldots$ (DID 121/POA)

A Tabela 3, a seguir, mostra os diferentes recursos, identificados no corpus, empregados para estabelecer uma relação temporal:

Tabela 3 - expressão das relações de tempo.

\begin{tabular}{|c|c|}
\hline CONECTIVO & FREQUENNCIA \\
\hline quando & $185(82,2 \%)$ \\
\hline logo que & $03(1,3 \%)$ \\
\hline desde que & $01(0,4 \%)$ \\
\hline enquanto & $04(1,8 \%)$ \\
\hline sem conectivo & $18(8,0 \%)$ \\
\hline outros $^{2}$ & $14(6,2 \%)$ \\
\hline TOTAL \\
\hline
\end{tabular}

\section{C) Relações de finalidade (ou propósito)}

Nas ocorrências analisadas, $100 \%$ das construções que expressam finalidade (ou propósito) foram introduzidas pelo conectivo para, na grande maioria das vezes seguido de uma forma verbal no infinitivo. Essa relação ocorreu com muita frequência no corpus, mas o que se evidenciou é que sua configuração gramatical quase não apresenta variações.

\footnotetext{
${ }^{2}$ Foram registradas, no corpus, várias expressões indicativas de alocação temporal, como no dia que, na hora que, uma vez que, logo depois de, depois que, nessa vez que, naquele tempo que, logo no primeiro ano que, etc., com funcionamento de conectivo temporal, conferindo tonalidades de sentido muito particulares aos enunciados.
} 
Assim como as construções temporais, as que expressam finalidade podem ser colocadas antecedendo a nuclear, seguindo-se a ela, ou intercaladas. Nos dados investigados, a posição posposta é a de maior frequência. Como já se salientou, essa posição é geralmente ocupada pela informação de maior relevância, o que se evidencia em (11):

(11)

Doc. - agora me diga o seguinte $\downarrow$ você diz que pegou o empréstimo pra poder pagar L1 - $\quad\left[\begin{array}{l}\text { a viagem e a saída... } \\ \text { pagar a viagem } \downarrow . . .\end{array}\right.$

Doc. - quais são as operações que você teve que fazer pra conseguir esse empréstimo?

L1 - pra conseguir o empréstimo?...

Doc. - que normalmente a pessoa faz?...

L1 - bom $\downarrow$ o que... o que acontece é o seguinte $\downarrow[\ldots]$ (D2 355/RJ)

Note-se que a construção final introduzida pelo documentador é a parte que é repetida por L1, numa demonstração de que essa é a parte interpretada como a informação de maior saliência. A liberdade quanto à posição dos satélites de finalidade é tal que se podem intercalar porções de texto, na maioria das vezes comentários, de caráter parentético, entre as duas partes conectadas pela relação final. No corpus, as marcas formais empregadas pelos falantes para estabelecer relações de finalidade foram as seguintes:

Tabela 4 - expressão da relação de finalidade.

\begin{tabular}{|c|c|}
\hline CONECTIVO & FREQUENCIA \\
\hline para ( + forma reduzida de infinitivo) & $199(93,9 \%)$ \\
\hline para (+ forma desenvolvida) & $10(4,7 \%)$ \\
\hline sem conectivo & $03(1,4 \%)$ \\
\hline TOTAL & $\mathbf{2 1 2}$ \\
\hline
\end{tabular}

Uma observação importante a ser feita, ainda, é a possibilidade de as construções finais serem postas numa cadeia coordenada, ou simplesmente justapostas, como em (12), a seguir.

(12)

Loc - [sobre o circo] [...] então a aquela vez surgiu oportunidade eu fui $\downarrow$ agora TEM QUE TER um certo espaço também pra pra eles poderem trabalha:: $r$ com os anima::is e com... com eles mesmo no picadeiro e pra a gente também não estar em CIma deles... pra ver o... espetáculo $\downarrow$ (DID 121/POA)

\section{D) Relações de condicionalidade}

Dentre todas as relações semânticas arroladas pela tradição linguística, a de condicionalidade parece ser a que mais tem intrigado os estudiosos, tanto linguistas quanto filósofos, o que resultou em variados trabalhos, nos quais foram abordados diferentes aspectos 
da relação condicional. A análise aqui realizada vem reiterar o que já está assentado sobre a condicionalidade em português: essa relação é privilegiadamente introduzida pelo conectivo se, como se pode observar na Tabela 5.

Tabela 5 - expressão da relação de condicionalidade.

\begin{tabular}{|c|c|}
\hline CONECTIVO & FREQUENCIA \\
\hline se & $125(87,4 \%)$ \\
\hline desde que & $05(3,5 \%)$ \\
\hline sem conectivo & $13(9,1 \%)$ \\
\hline TOTAL & \\
\hline
\end{tabular}

De um ponto de vista lógico, a condicionalidade é representada por uma construção binária, em que a proposição condicionada chama-se apódose e a condicionante chama-se prótase. A relação entre a prótase (p) e a apódose (q) é representada pela fórmula se p, então q, sendo o conteúdo de $\mathbf{p}$, nessa fórmula, entendido como condição necessária e suficiente para a realização do conteúdo de q. No entanto, o que se evidencia nos dados analisados é que poucos são os enunciados que se enquadram inteiramente nesse esquema lógico.

As construções condicionais são geralmente subdivididas em três tipos: (a) as factuais (ou reais), que relacionam conteúdos no mundo real, como se pode verificar em (13); (b) as contrafactuais (ou irreais), em que o conteúdo expresso pela prótase é irreal, como se observa em (14); e (c) as eventuais (ou potenciais), em que o conteúdo expresso pela prótase pode realizar-se ou não, ficando a realização do conteúdo da apódose na dependência de a condição ser preenchida, ou não. Essa eventualidade é ilustrada em (15).

(13)

Loc. - então a gente toma vinho de acordo também com o tipo de comida... se é carne... aqueles hábitos que a gente tem $\downarrow$... se é carne é vinho tinto... se é peixe a gente usa vinho branco... mas a gente to/ [interrompida pelo doc.] (DID 328/RJ)

(14)

L2 - [...] e:: eu acho que:... o dinheiro todo que eu pudesse... se eu ganhasse assim... na loteria e tal eu não jogaria em mercado de capita:is nada disso eu sempre ficaria em imóveis $\downarrow$... (D2 355/RJ)

L2 - [...] depois o café:: em casa o café é muito demorado... muito complicado quer dizer então até eles comerem todas as coisas que fazem... parte do café eles demo::ram um briga com o outro a divisão tem que ser ABsolutamente exata... porque se um tiver mais do que o outro sai um monte de briga na realidade não acabam tomando tudo não comendo tudo que tem $\downarrow$... (D2 360/SP) 
Neves (1999a) analisa o valor argumentativo desses três subtipos de condicionais, e conclui que tanto as factuais, por sua característica de expressar condição preenchida + conclusão, quanto as eventuais, por sua característica de expressar condição eventualmente preenchida + conclusão possível, contribuem para o jogo argumentativo.

Importa ainda mencionar a possibilidade de a relação condicional contrafactual ser codificada gramaticalmente, pelo modo verbal, com ausência do elemento conectivo, como se demonstra em (16).

(16)

[...] as plantas é que dão o oxigênio ao ar... pela fotossíntese $\downarrow$... e os animais sempre viveram à sombra das plantas $\downarrow$... os animais só podem existir... porque se alimentam... das comidas FEItas... pelas plantas $\downarrow$... não fossem as plantas nós animais não existiríamos $\downarrow$... por isso é que a gente combate a o horror que é: destruir árvores inutilmente $\downarrow \ldots$ (DID 216/RE)

\section{E) Relações de concessão}

Em uma construção concessiva, a oração subordinada e a nuclear guardam uma relação tal que o que se afirma no enunciado é que o conteúdo expresso na nuclear se realiza, a despeito da realização do conteúdo expresso no satélite. Analisando o comportamento das concessivas, a maioria dos autores as tem aproximado das coordenadas adversativas, já que ambas as construções operam no sentido de "contrariar uma expectativa". No entanto, como se verá adiante, as construções concessivas podem ser aproximadas também das causais e das condicionais, por terem traços comuns.

No texto conversacional, as construções concessivas são introduzidas principalmente pelos conectivos embora e apesar (de; que; ou de que), que apresentaram quase a mesma frequência nos dados investigados. Outros conectivos introdutores da concessão, e sua frequência no corpus, são apresentados na Tabela 6.

Tabela 6 - expressão da relação de concessão.

\begin{tabular}{|c|c|}
\hline CONECTIVO & FREQUENCIA \\
\hline embora & $20(31,3 \%)$ \\
\hline apesar (de) & $21(32,9 \%)$ \\
\hline se bem que & $12(18,8 \%)$ \\
\hline apesar (que) & $06(9,4 \%)$ \\
\hline mesmo que & $03(4,6 \%)$ \\
\hline mesmo + gerúndio & $01(1,5 \%)$ \\
\hline a não ser que & $01(1,5 \%)$ \\
\hline TOTAL & \\
\hline
\end{tabular}


A partir da observação de que a relação instaurada entre o satélite concessivo e a oração nuclear pode dar-se de diferentes maneiras, gerando diferentes efeitos de sentido, os estudos sobre as construções concessivas as têm dividido, assim como com as condicionais, em três subtipos: factuais (ou reais), contrafactuais (ou irreais), e eventuais. As concessivas factuais são aquelas em que o conteúdo expresso no satélite se realiza, e, apesar disso, também se realiza o conteúdo expresso na nuclear. É o que acontece em (17), em que a retomada anafórica do percentual recebido de salário, na nuclear, contribui para entrelaçar mais ainda as duas partes postas em relação.

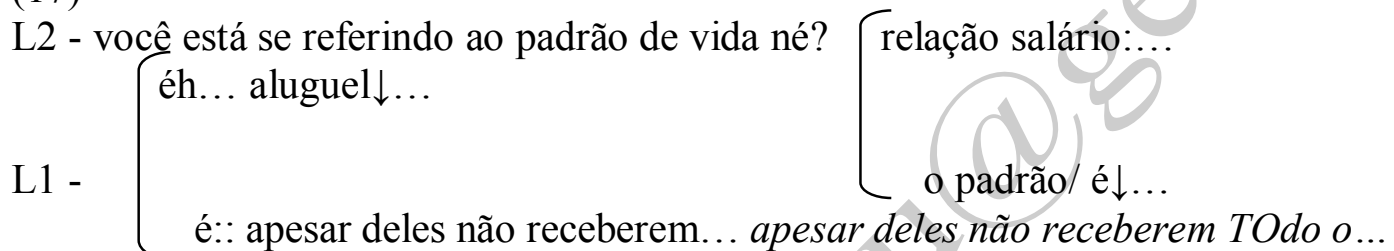
o dinheiro que ganham receberem sessenta por cento do... do salário... esses sessenta por cento dão um padr/ dão um padrão de vida muito alto $\downarrow$... (D2 355/RJ)

Concessivas contrafactuais são aquelas em que o conteúdo expresso no satélite não se realiza, e, apesar disso, também não se realiza o conteúdo expresso na nuclear. No corpus analisado, não foi detectado nenhum caso de concessiva contrafactual típica, mas em uma das ocorrências, a contrafactualidade é inferida por meio de dados contextuais. As concessivas eventuais são aquelas em que o que está expresso no satélite tem a possibilidade de realizar-se, mas assim mesmo o conteúdo expresso pela nuclear pode realizar-se, ou não. É o que se pode observar em (18).

L1 - [...] agora essa essa nesse mês como a UPC não aumentou e como diminuiu o número de UPCs... o que vai acontecer é que: uh: eu vou pagar um pouquinho menos $\downarrow$... no outro mês vou pagar um pouquinho menos... porque diminuiu as UPCs $\downarrow$ apesar de no outro diminuir a UPC eu vou pagar MUIto mais do que paguei a primeira por quê? a UPC vai subir não sei pra quanto $\downarrow$... (D2 355/RJ)

É consensual, nos trabalhos sobre a relação concessiva (ZAMPRONEO, 1998, 2001; NEVES, 1999b), a ideia de que a concessão pressupõe uma objeção de inferência. Ou seja, a inserção de uma construção concessiva seria motivada pela antecipação de uma inferência, que é negada. É o que acontece, por exemplo, na ocorrência (19), abaixo, em que o documentador pergunta à locutora o que ela acha dos apresentadores de programas televisivos, e a locutora começa a listar os apresentadores que conhece, acrescentando comentários gerais sobre cada 
um deles. Ora, sabendo-se que, na nossa cultura, o gosto por alguns programas de televisão pode ser interpretado como sinal de baixa cultura, e que um dos critérios de seleção dos informantes do Projeto NURC foi exatamente o de eles serem representantes de um falar “culto", a locutora, de certa maneira, "protege-se" contra possíveis julgamentos negativos por parte do documentador. Observe-se:

(19)

Doc. - e (entre) [apresentadores] nacionais mais famosos?

Loc. - [...] o Jota Silvestre acho fabuloso $\downarrow$... acho que ele... prende a atenção da gente $\downarrow$... ele é uma pessoa simpática agradável... comunicativa também e respeita o outro o próximo $\downarrow$... o Moacir Franco também é apresentador eu gosto... dele $\downarrow$... o Sílvio Santos também... mas (na) apesar de não assistir o programa dele $\downarrow . .$. (DID 121/POA)

Essa "negação de inferência" opera-se quando a concessiva é posposta. Na posição anteposta, ela funciona no sentido de reduzir o espaço para a inferenciação, potencializando o efeito de "preservação de face" (Goffman, 1970; Galembeck, 1997) da concessiva, a ser discutido adiante.

\section{F) Relações de comparação}

O estabelecimento de uma relação comparativa efetua-se a partir da seleção de dois estados de coisas, que, cotejados, são apresentados como tendo algo em comum. Comparações são tão abundantes no material analisado que se pode afirmar, grosso modo, que a comparação é a base da nossa percepção da realidade, e, por isso, manifesta-se linguisticamente com acentuada frequência. Contudo, relações comparativas configuradas por construções adverbiais apresentam baixa frequência no corpus, e, nos casos em que ocorrem são, na maioria das vezes, introduzidos pelo conectivo como. É o que mostra a Tabela 7, abaixo:

Tabela 7 - expressão da relação de comparação.

\begin{tabular}{|c|c|}
\hline CONECTIVO & FREQUENNCIA \\
\hline como & $41(91,1 \%)$ \\
\hline que nem & $02(4,5 \%)$ \\
\hline de acordo com & $01(2,2 \%)$ \\
\hline conforme & $01(2,2 \%)$ \\
\hline TOTAL & $\mathbf{4 5}$ \\
\hline
\end{tabular}

O conectivo comparativo que nem é raramente mencionado nos manuais, mas é muito frequente em contextos conversacionais distensos, como se observa em (20). 
(20)

Doc. - o que tu achas da publicidade em nosso rádio?

Loc. - olha eu acho que tanto no rádio como na televisão de vez em quando... tem publicidade demais propaganda DEmais $\downarrow$... era era propaganda sim e::... ma/ MAS como É necessário isso sabe? sem a propaganda eles não podem funcionar... tu tem que aguentar $\downarrow$ agora acho que seria interessante por exemplo que nem é feito na Europa que cada... ah:.... hm cada casa contribui com tanto por mês... e então:: os que têm televisão e rádio contribuem com tanto por mês e aquilo é pra:: pra televisão $\downarrow$ (DID 121/POA)

Analisando-se as partes que são postas em comparação, vê-se que o falante pode relacioná-las não somente na base da factualidade, mas também na base da contrafactualidade. Nos dados analisados, em todas as ocorrências em que esse fato se verificou, a contrafactualidade foi marcada pelo se. É o que ocorre em (21), a seguir.

(21)

L1 - [comentando sobre o fato de que tomar bebida alcoólica é um tabu na Suécia] [...] eu tenho um amigo meu francês que foi... e ele queria comprar uma garrafa de vinho... pra levar pra uma... um um... um jantar que ia $\downarrow$... diz que todo mundo que ele perguntava na rua... dizia perguntava "senhor onde é que eu posso comprar bebida alcoólica ou comprar vinho?" as pessoas olhavam para ele como se ele estivesse perguntando "onde é que tem um bordel aqui nessa rua?" ((risos))... (D2 $355 / \mathrm{RJ})$

$\mathrm{Na}$ classificação das gramáticas tradicionais, arrolam-se, na lista das chamadas “subordinadas adverbiais", construções “conformativas". Pela análise aqui realizada, verificouse que o que está na base das conformativas é o mecanismo da comparação. Isso justifica a inclusão das construções de conformidade no quadro das relações de comparação.

É interessante observar que, das ocorrências de construções conformativas, a grande maioria representa uma avaliação metalinguística do falante, o que vem corroborar a ideia, consensualmente aceita, de que o falante realiza, durante a conversação, um intenso trabalho de monitoração dos enunciados que produz. Veja-se a ocorrência (22), abaixo:

(22)

L1 - [comparando a merenda servida em escolas de periferia com a servida em outras escolas "melhores"] o outro era tipo almoço $\downarrow$... aqui mais... é tipo merenda mesmo... como a gente costuma chamar... né? (DID 355/RJ) 
As construções conformativas têm também uma importante função coesiva na conversação, no sentido de recuperar, no momento agora, momentos anteriores do texto conversacional. Ao fazer isso, o falante "amarra" conteúdos proferidos em momentos temporalmente distanciados. É o que se observa em (23), a seguir.

(23)

Doc. - você não conheceu outro tipo de televisão a não ser a nossa?

Loc. - conheci (conheci) por exemplo na Europa conheci a televisão mas lá bom lá o governo também cuida... dos programas e... do do nível dos programas e há:: censura... e é assim que nem eu disse a propaganda... não é feita:: pela televisão $\downarrow$... o::... o po/ pessoal todo é que tem que dar uma certa quantia por mês... e:: hm:: todos os meses pra:: pra essas propagandas $\downarrow$... (DID 121/POA)

A análise evidenciou, então, que as construções adverbiais, embora sejam uma opção do falante, são muito frequentes na conversação. Cabe analisar, agora, o papel que têm essas construções para administrar e manter a interação, em contextos de conversação face a face.

\subsection{Análise qualitativa de dados}

Quando duas pessoas decidem participar de uma conversação, o que na verdade decidem é relacionarem-se por meio da linguagem. Conversar não é simplesmente "trocar informações", no sentido literal. Aliás, isso talvez seja o que menos se faz durante uma conversa. Conversar é expor-se. É mostrar-se como um "ser-no-mundo", aqui e agora. A "troca" que se realiza na conversação é o intercâmbio inevitável, e positivo, que acontece sempre que dois seres humanos se dispõem a "inter-agir", e é nessa "inter-ação", afinal, que se constituem como humanos.

Nesse quadro, inserem-se as construções adverbiais. Elas participam da composição do texto na conversação, sendo uma opção organizacional de que dispõe o falante, e servindo, portanto, a seus propósitos comunicativos. Esses propósitos, nos quais estão envolvidas as relações adverbiais, podem ser analisados segundo três perspectivas:

A) na perspectiva do falante, a partir da qual serão arrolados os propósitos comunicativos focados prioritariamente na pessoa que fala;

B) na perspectiva do ouvinte, a partir da qual se agrupam os propósitos comunicativos focados no(s) interlocutor(es); e

C) na perspectiva da interação, a partir da qual são listados os propósitos comunicativos focados na negociação que se realiza durante a conversação. 
É importante frisar que essa diferença de perspectiva só tem validade como opção metodológica de organização do trabalho. Na realidade da conversação, todos esses propósitos estão imbricados, e operam concomitantemente.

\subsubsection{Propósitos focados no falante}

\section{Preservação da face}

Face foi um termo introduzido por Goffman (1970), para significar a autoimagem pública do falante. Afirmamos, anteriormente, que "conversar é expor-se". No entanto, o falante dispõe de estratégias por meio das quais pode não se expor completamente, "protegendo-se", assim, de avaliações indesejadas da parte de seu(s) interlocutor(es). Essas estratégias de preservação da face são codificadas por várias construções, e correspondem, principalmente, a explicações e justificativas.

As explicações são codificadas principalmente por meio de construções causais (de atos de fala), como em (24), e concessivas, como em (25).

Loc. - geralmente eu almoço em volta de/ por volta de meio-dia $\downarrow$... e janto por volta das sete horas sete e meia $\downarrow$... e depois disso não faço mais nada...

Doc. - depois do jantar ( )

Loc. - não $\downarrow$... não como na:da $\downarrow$... tomo café $\downarrow$... eu tomo muito cafezinho durante o dia $\downarrow$... que eu fumo também né? (DID 328/RJ)

L1 - suco de la/ de de de bergamota por exemplo... põe ela na centrífuga... (por um instante)

L2 - é:

L1 - duas ou três dúzias de: de bergamota PÁ... faz uma jarra... que/ quer dizer saudável... se bem que lá em casa... se faz isso com mais frequência por causa da gurizada $\downarrow$... (D2 291/POA)

Também funcionam na preservação da face algumas construções finais, pelas quais o falante apresenta uma justificativa para um ato de fala, como em (26), a seguir.

Loc - bem mas digamos assim do ponto de vista da... da organização desses estabelecimentos onde se ministra o ensino... eh... segundo assim a idade né? por exemplo criancinhas... eh... vão a que tipo de escola né? pra a gente ver se a gente pega um pouco da... bem pequenininhos qual é o tipo de colégio [interrompida pelo 


\section{doc.] (DID 231/SSA)}

\section{Monitoramento das expressões linguísticas}

A atividade de monitoramento das expressões linguísticas pode ser analisada em relação ao emprego de determinados termos e/ou expressões, atividade para a qual as construções comparativas/conformativas são as preferencialmente selecionadas pelo falante; ou à relevância do conteúdo expressado. Nesse caso, o monitoramento é expresso, principalmente, por construções causais (introduzidas por já que). Observe-se a ocorrência (27), abaixo, na qual a locutora demonstra perceber que a expressão empregada por ela (quebrar o galho) é marca de um registro que pode ser interpretado como inadequado para aquele contexto de fala.

\section{(27)}

Doc. - e a proliferação das lanchonetes na vida do carioca heim?

Loc. - é isso realmente: tá aumentando e: é... é um é um recurso que se tem pra você poder comer justamente pro tipo de vida que se $\mathrm{u} /$ que se tem aqui no Rio né?... geralmente... o pessoal tem mais... sempre quase sempre mais de um emprego e não tem oportunidade de... senta:r pra fazer uma refeição calma né? tranquila... a lanchonete serve pra quebrar o galho né? como a gente costuma dizer $\downarrow$... e: também porque é mais barato né?... mais em conta $\downarrow$... (DID 328/RJ)

\section{Busca de apoio para os argumentos}

O falante tem a opção de não assumir, sozinho, a autoria dos argumentos que apresenta em seu discurso, buscando, então, o apoio de outras fontes, para respaldar seus argumentos. Um recurso que tem para conseguir esse apoio é a utilização das construções comparativas/conformativas, como se pode ver na ocorrência (28):

(28)

L1 - agora você falou em: em estatal não é? O Brasil também está caminhando pra economia estatal e como eu leio aí nos jornais... a gente não é dessa área... né? quer dizer... desse setor... mas você vê... um absurdo o Brasil... a Companhia Siderúrgica Nacional... no balanço apresentado... alto prejuízo... como é que uma emp/ uma companhia de aço produtora de de de aço... pode dar prejuízo? (D2 355/RJ)

\subsubsection{Propósitos focados no ouvinte}

1. Explicações

Já foi mostrado que explicações podem ser centradas no falante, funcionando na atividade de preservação da face. Mas explicações podem também ser focadas no ouvinte (e 
aqui são verdadeiras explicações), quando demonstram o cuidadoso trabalho do falante para que o ouvinte acompanhe integralmente o(s) sentido(s) do texto. Explicações focadas no ouvinte ocorrem principalmente quando o falante julga que deixou de fornecer algum dado que ele considera relevante para a compreensão por parte do seu interlocutor. É o que acontece em (29):

(29)

Loc.- no Amazonas por exemplo que nós estivemos em Manaus... ah nós passamos uma tarde num num lugar onde eles serviram uma refeição... e depois então era só frutas $\downarrow$... mas frutas realmente que eu nunca havia visto $\downarrow$... (DID 328/RJ)

Nessa ocorrência, a locutora queria chamar a atenção para a diferença entre as frutas do Norte/Nordeste, em comparação com as do Sudeste. O Tema no Amazonas estava sendo introduzido na conversação, sendo essa a primeira vez que ele ocorria. Daí a necessidade, sentida pela locutora, de explicar por que tinha "autoridade" para comentar sobre as frutas do Amazonas, explicação codificada na forma de uma construção adverbial.

Observe-se que, em termos de progressão textual, a inserção de fragmentos explicativos, como o da ocorrência (29), opera ruptura do fluxo informativo, fazendo o texto retroceder. Ainda assim, o falante opta por inseri-los, por julgá-los relevantes para a compreensão por parte do ouvinte.

2. Preparação de molduras

Chafe (1984) postula que algumas construções adverbiais funcionam para criar um espaço mental, ou uma "moldura de referência", na qual seria inserido um determinado conteúdo. Obviamente, a interpretação das construções adverbiais como molduras de referência só é possível quando as construções adverbiais são antepostas à oração nuclear. Assim, em (30), abaixo,

(30)

Loc. - bom... eu quando:: tinha uns dezoito quinze a dezoito anos eu estudei balê $\downarrow$... e tive oportunidade de trabalhar fazer uma cena como o:: balê russo $\downarrow$... (DID 234/SP)

o satélite temporal pode ser analisado como uma moldura temporal, dentro da qual o conteúdo eu estudei balé deve ser interpretado. Das construções adverbiais aqui analisadas, as que podem 
ser consideradas molduras de referência são as temporais, as condicionais, e algumas concessivas.

Em narrativas, uma moldura temporal pode também ser inserida para refazer outra moldura temporal já aberta anteriormente, de modo que, em trechos mais longos, várias molduras podem ser abertas, nas quais vão sendo alocados os diferentes conteúdos que compõem a narrativa. A esse respeito, veja-se a ocorrência (31), abaixo.

L1 - mas eu também já viajei daqui... pra Itaipé...

Doc. - ( )

L1 - nos trens da Leste Brasileiro $\downarrow$ esses daí são ((rindo)) agradabilí:ssimos $\downarrow$...

Doc. - e como é que era?...

L1 - ah... a estrada é uma maravilha $\downarrow$ quando você sai daqui tem um pedacinho que é... a linha coberta de brita de modo que a coisa já embola $\downarrow$... e você apenas é sacolejado de um lado ((rindo)) pra o outro $\downarrow$... tem certas subidas que você salta... e vai passean:do quando chega em cima (vo)cê espera pega ((rindo)) o trem novamente e desce $\downarrow$... pra descer $\downarrow$... e depois que passa o leito britado que você pega já o leito sem a proteção da brita aí então é uma maravilha $\downarrow$ (DID 231/SSA)

Nessa ocorrência, abre-se uma primeira moldura [quando você sai daqui], na qual se inserem alguns conteúdos. Em seguida, essa moldura é substituída por outra [quando chega em cima], em que se inserem novos conteúdos. Dessa forma, a narrativa vai sendo construída e organizada.

\subsubsection{Propósitos focados na interação}

1. Revelação de propósitós

O falante pode optar por revelar os propósitos que tem em relação ao conteúdo que deseja expressar. Ao revelar suas expectativas, posiciona-se em relação à enunciação, como se pode ver em (32):

L1 - vamos vamos ver as perplexidades do nosso mundo atual eu ainda há pouco gritei que Nietzsche dizia que o homem... se desmistificaria... e a gente sente a desmistificação... MAS... pra você ver como eu tô perplexo e como que e como conFEsso essa perplexidade... seria Efetivamente DESmistificação quando o mundo TO:DO... QUAse... admite... áh: as religiões negras... você vê no Brasil... cerca de oitenta por cento do povo [interrompido pelo interlocutor] (D2 005/RE) 


\section{Contrastes (ressalvas)}

Algumas construções adverbiais podem ser usadas quando o falante deseja apresentar enunciados em contraste. Para esse fim, as construções concessivas são as mais utilizadas, a exemplo de (33),

\section{(33)}

L1 - então ele trabalha

$\mathrm{L} 2-(\mathrm{)})$

L1 - NA Secretaria da Justiça...

L2 - ahn ahn

L1 - se... bem que... o lugar dele seja nos Transportes né? (D2 360/SP)

em que as duas ideias - trabalhar na Secretaria da Justiça e ser efetivamente da Secretaria dos Transportes - são apresentadas, pelo falante, de maneira contrastiva. Desse modo, construções concessivas cumprem, na conversação, a importante função de apresentar ressalvas. $O$ falante tem a opção de apresentá-las antecipadamente, anulando o efeito que podem provocar no interlocutor, ou posteriormente, intensificando esse efeito, principalmente quando apresentadas após uma pausa de final de frase.

\section{Considerações finais}

Este trabalho apresenta uma síntese dos resultados de pesquisa acerca das construções adverbiais, tomando por base principalmente as teorias funcionalistas de Halliday (1985), Mathiessen \& Thompson (1988), e Dik (1989, 1997). O que se buscou averiguar foi o papel das construções adverbias na interação, representada aqui pela conversação face a face.

Contrariamente ao que se faz na gramática tradicional, em que os valores semânticos são dados como preexistentes à interação, a análise aqui realizada evidenciou que a "bagagem semântica" resultante do inter-relacionamento entre um núcleo e um satélite adverbial não existe a priori, mas é gerada na situação interativa (e a partir dela), quando falante e ouvinte constroem conjuntamente o texto conversacional.

A análise comprovou que a opção pelo emprego de uma construção adverbial visa a atender os propósitos comunicativos do falante, propósitos esses que surgem no curso da conversação. Fica, então, evidenciado que é na interação, afinal, que se encontram as motivações para a ocorrência das relações adverbiais. Essas motivações foram aqui analisadas a partir de três perspectivas: na do falante, na do ouvinte, e na perspectiva da interação mesma. 
$\mathrm{Na}$ perspectiva do falante, foram encontrados propósitos ligados às estratégias de preservação da sua face, de monitoramento das expressões linguísticas e de busca de apoio para a argumentação. São prioritariamente recursos linguísticos de que o falante dispõe para administrar sua fala e manter a conversação.

$\mathrm{Na}$ perspectiva do ouvinte, foram detectados os propósitos relacionados com as estratégias usadas pelo falante no sentido de assegurar-se de que seu interlocutor acompanha sua fala, e alcança, por meio dela, a integridade dos sentidos que deseja veicular. Os recursos linguísticos usados para esse fim foram aqui referidos como a "inserção de segmentos explicativos" e a "preparação de molduras".

$\mathrm{Na}$ perspectiva da interação, foram identificados os propósitos ligados à atitude do falante em relação a um determinado conteúdo. Os recursos linguísticos de que dispõe o falante foram referidos, neste trabalho, como "revelação de propósitos" e "apresentação de contrastes (por ressalvas)".

Como se pode observar, nenhum desses propósitos, nos quais estão envolvidas as relações de hipotaxe adverbial, preexiste à interação. É no dinamismo da conversação que eles emergem e motivam certas construções.

\section{Referências bibliográficas}

BEAMAN, K. Coordination and subordination revisited: syntactic complexity in spoken and written narrative discourse. In: TANNEN, D. (ed.). Coherence in spoken and written discourse. Norwood, N.J.: Ablex, p. 45-80, 1982.

BLANCHE-BENVENISTE, C. Língua falada e ensino. (Tradução de Giselle M. de Oliveira). In: I Encontro Nacional sobre Língua Falada e Ensino, 1995, Maceió. Anais. Maceió, AL, 1995. p. 11-26.

BROWN, G.; YULE, G. Discourse analysis. Cambridge: Cambridge University Press, 1983. DOI: http://dx.doi.org/10.1017/CB09780511805226

CAStilho, A. T. de. A predicação adverbial no português falado. 1993, Tese (LivreDocência) - Universidade de São Paulo, São Paulo, 1993.

. A língua falada e sua descrição. In: Língua, filologia e literatura. Para Segismundo Spina. São Paulo: EDUSP, s/d. $120,1997$.

Língua falada e gramaticalização. In: Filologia e linguística portuguesa, n ${ }^{\circ}$, p.107. A língua falada no ensino de português. São Paulo: Contexto, 1998. 
CHAFE, W. How people use adverbial clauses. In: The Proceedings of the tenth annual meeting of the Berkeley Linguistics Society. Berkeley Linguistics Society, 1984.

DIK, S. The theory of functional grammar. Part 1. Dordrecht-Holland/ Cinnaminson - USA: Foris Publications, 1989.

. The theory of functional grammar. Part 2. Ed. by K. HENGEVELD. Berlin/New York: Mouton de Gruyter, 1997.

FÁVERO, L.; ANDRADE, M. L.; AQUINO, Z. Oralidade e Escrita. Perspectivas para o ensino de língua materna. São Paulo: Cortez, 1999a.

FÁVERO, L.; ANDRADE, M. L.; \& AQUINO, Z. A correção no texto falado. In: NEVES, M.H.M. (org.). Gramática do português falado. v.VII, São Paulo: Humanitas/FFLCH/USP; Campinas: Ed. da UNICAMP, 1999b. p.53-76.

FERNANDES, E. C. P.; PETIOT, P. Cláusulas concessivas nas produções oral e escrita. In: III Congresso da ASSEL-Rio. Rio de Janeiro: Associação de Estudos da Linguagem. Anais. Rio de Janeiro, 1994, p. 12-18.

FORD, C. Grammar in Interaction: Adverbial clauses in American English Conversations. Cambridge: University Press, 1993.

DOI: http://dx.doi.org/10.1017/CBO9780511554278

GALEMBECK, P. T. Preservação de face e manifestação de opiniões: um caso de jogo duplo. In: PRETI, D. (org.) O discurso oral culto. São Paulo: Humanitas, 1997. p.135-150.

GOFFMAN, E. Ritual de la interacción. Buenos Aires: Tiempo Contemporaneo, 1970.

HALLIDAY, M. A. K. An introduction to functional grammar. Baltimore: Edward Arnold Publishers, 1985.

. Spoken and written language. Oxford: University Press, 1989.

HILGERT, J. G. A qualificação discursiva no texto falado. In: URBANO, H. et al. (orgs.) Dino Preti e seus temas. Oralidade, literatura, mídia e ensino. São Paulo: Cortez, 2001. p.62-84.

KOCH, I. O texto e a construção dos sentidos. $2^{\text {a }}$ ed. São Paulo: Contexto, 1998.

LAKOFF, R. The pragmatics of subordination. In: Proceedings of the 10th. annual meeting of the Berkeley Linguistics Society, p.437-449, 1984.

LEVINSON, S. Pragmatics. Cambridge: Cambridge University Press, 1983.

MARCUSCHI, L. A. Bases para identificação de diferenças e semelhanças no contínuo falaescrita. In: IX Encontro Nacional da ANPOLL, João Pessoa, 1995. Anais. v.2, tomo II, p.11881198, João Pessoa, PB, 1995. 
. Concepção de língua falada nos manuais de português de $1^{\circ}$. e $2^{\circ}$. graus: uma visão crítica. In: Trabalhos em Linguística Aplicada, 30, p.39-79, 1997.

. O tratamento da oralidade nos PCN de língua portuguesa de $5^{\mathrm{a}}$. a $8^{\mathrm{a}}$. séries. In: SCRIPTA, v. 2, no. 4, Belo Horizonte, MG: Ed. da PUC Minas, p. 114-129, 1999a.

. A hesitação. In: NEVES, M.H.M. (org.). Gramática do português falado, v.VII, São Paulo: Humanitas/FFLCH/USP; Campinas: Ed. da UNICAMP, p.159-194, 1999 b.

. Da fala para a escrita: atividades de retextualização. São Paulo: Cortez, 2001.

MATTHIESSEN, C.; THOMPSON, S. The structure of discourse and 'subordination'. In: HAIMAN, J.; THOMPSON, S. (eds.). Clause combining in grammar and discourse. Amsterdam, Philadelphia: John Benjamins, 1988. p.275-329.

NEVES, M. H. M. et al. Análise do uso de algumas palavras de relação. In: Estudos Linguísticos. v. 1, p. 321-333, 1993.

NEVES, M. H. M. A gramática funcional. São Paulo: Martins Fontes, 1997.

. As construções condicionais. In: NEVES, M.H.M. (org.) Gramática do português falado, v. VII, São Paulo: Humanitas/FFLCH/ USP; Campinas: Ed. da UNICAMP, 1999a. p.497-544.

. As construções concessivas. In: NEVES, M.H.M. (org.) Gramática do português falado, v. VII, São Paulo: Humanitas/FFLCH/ USP; Campinas: Ed. da UNICAMP, 1999b. p.545-591.

. Gramática de usos do português. São Paulo: Ed. da UNESP, 2000.

OCHS, E. Planned and unplanned discourse. In: GIVÓN, T. (ed.) Discourse and syntax. New York: Academic Press, 1979, p. 51-80.

PAIVA, M.C. Empregos de 'porque' no discurso oral. In: DELTA, 11:1, p.27-39, 1995.

PRETI, D. Alguns problemas interacionais da conversação. In: PRETI, D. (org.). Interação na fala e na escrita. São Paulo: Humanitas/FFLCH/ USP, 2002. p.45-66.

RODRIGUES, A. C. S. Língua falada e língua escrita. In: PRETI, D. (org.). Análise de textos orais. $2^{\text {a }}$ ed. São Paulo: FFLCH/USP, 1995.

SCHIFFRIN, D. Approaches to discourse. Massachusetts/Oxford: Blackwell, 1994.

SWEETSER, E. From etymology to pragmatics. (Cambridge Studies in Linguistics 54). Cambridge: Cambridge University Press, 1990. 
VANDERVEKEN, D. Illocutionary logic and the theory of discourse. In: SOARES, M. E. (org.) Boletim da ABRALIN, v.25, Fortaleza, 2000. p.21-47.

ZAMPRONEO, S. A hipotaxe adverbial concessiva no português escrito contemporâneo do Brasil. 1998. Dissertação (Mestrado), Universidade Estadual Paulista, Araraquara, 1998.

. O papel dos satélites concessivos na estrutura subjacente da frase. In: NEVES, M.H.M. (org.) Descrição do português: definindo rumos de pesquisa. Araraquara: FCL/Laboratório Editorial/ UNESP; São Paulo: Cultura Acadêmica Editora, 2001, p.79-100.

Artigo recebido em: 02.09.2013

Artigo aprovado em: 02.12.2013 